\title{
The Effectiveness of Product Placement: The Influence of Product Placement towards Consumer Behavior of the Millennial Generation
}

\author{
Liew Chee Kit and Elizabeth Lim Qui P'ng
}

\begin{abstract}
This study examines the influence of product placement in television shows and movies toward consumer behavior. 100 respondents from the Klang Valley, aged from 18 to 25 participated in this research. The methodology uses convenience sampling. The data analysis is done with the SPSS windows software. This study integrates the Theory of Reasoned Action to test five different hypotheses. The main findings show that beliefs of a person about product placement can affect the individual's attitude. In addition, normative norms have a significant relationship with subjective norms. Both attitude and subjective norms have a direct effect on purchase intention. Lastly, purchase intention will affect a person's consumer behavior. Some suggestions are given to advertisers and marketing researchers respectively.
\end{abstract}

Index Terms-Consumer behavior, product placement, purchasing intention, theory of reasoned action.

\section{INTRODUCTION}

Product placement is defined as placing a brand in media content to affect consumer behavior [1]. In other words, companies pay movie or television program makers or licensees a sum of money in order to have their product or brand name displayed during the movie or show for a certain period of time [2]. With celebrities endorsing a particular brand, it automatically brings a positive image of the product and hence, influences customers' perceptions about the brand [3].

An example of product placement in a television program is in American Idol, a reality singing competition to find new talent to represent America for the year. On the table of the panel of judges, a red glass with the Coca-Cola logo is placed in front of each judge during the competition [4]. The contestants see the glasses and so do the audience, especially those watching through television. Besides that, Internet users who browse the American Idol website to check out videos and pictures of the competition will also be exposed to the glasses. Other examples of television shows are: Friends, Sex and the City, Desperate Housewives, and House. Oreo biscuits and cans of Budweiser are often shown in Friends;

Manuscript received July 18, 2013; revised September 24, 2013. This work was supported in part by the Infrastructure University Kuala Lumpur, Malaysia. Authors would like to identify and thank the Infrastructure University Kuala Lumpur, Malaysia for all financial supports in this paper titled: The Effectiveness of Product Placement: the Influence of Product Placement towards Consumer Behavior of the Millennial Generation.

Liew Chee Kit is with the Infrastructure University Kuala Lumpur, Kajang 43300 Malaysia (e-mail: liewck@iukl.edu.my).

Elizabeth Lim Qui P'ng is with the Sri Sempurna International School, Kuala Lumpur, Malaysia (e-mail: zabethetc@gmail.com). whereas a whole episode of Sex and the City featured an ad for Absolut Vodka; Buick vehicles are used by casts in Desperate Housewives; and in House, stars can be seen using Apple's MacBook in the show.

Movies are not exempted from product placements; instead, it is seen as the new advertising avenue for advertisers. An example is the recent famous movie, Transformer 3: Revenge of the Fallen. Product placements for big names include: General Motors, Apple, Mercedes Benz, Lenovo, CNN, Fox News, "Bee-Otch" air freshener, and a few other products from China. Brand Channel, an online exchange website about branding, awarded Transformer 3 the 2011 Award for "Achievement in Product Placement in a Single Film."

Consumer behavior is defined as how a customer searches for information, when they purchase a product, how they use it, their post-evaluation and how they categorize products to gratify their wants [5]. Consumer behavior is based on the consumer's decision making process, which involves: 1) Need recognition [5]. Consumers discover a need when they have a problem. Therefore, they will 2) search for a product or service to satisfy the need via internal and external sources. An internal source includes past experience; whereas external sources comprise of marketing and noncommercial information. Before making the decision, they will 3) evaluate alternatives which are derived from brands, known and unknown to them [6]. After all of these, the consumer will have a 4) post-purchase evaluation which will either make them repeat the purchase or regret purchasing the good or service [6]. However, it is vital to note that consumers do not go through every single step of this process because their decision is also based on whether their problem or need is solved by purchasing something.

Product placement in Hollywood movies first started in 1982 in the movie E.T. The Extra-Terrestrial [1]. The movie featured an alien who was following a trail of Hershey's Reese's Pieces to his new home [1]. Reese's Pieces had an increase in sales, which created the new advertising strategy of product placement [1]. However, scholars believed that product placement began a long time before this where it was implemented in stage performances and art [7]. An example of product placement in paintings is a Bass Beer by Edouard Manet [7]. Likewise, product placement in novels such as The Pickwick Papers by Charles Dickens's started in 1836 [1]. The name "Pickwick Papers" was taken from the London-to-Bath carriage line which was mentioned in a small part in the story although the main character riding on the carriage was mentioned in the center of one of the stories [1]. Meanwhile, product placements in plays and posters started off with Sarah Bernhardt, who was seem using La Diaphane 
powder in a play [1].

The term 'product placement' was not used until the late 1980 's and it was defined as putting in a brand or logo in media content [1]. Prior to that, terms such as exploitation, tie-ups, and tie-ins, were used to represent product placement [1]. The term "exploitation" was used to represent a kind of publicity that might generate attendance [1]. Slowly, the term evolved to "tie-ups" and "tie-ins advertising" which meant that the actor had to endorse a product on-screen or off-screen or both, and the return on investment was free props.

Although the beginnings of product placement was the outcome of intermarrying family-ties, it became more and more popular in motion pictures when people realized that there was a win-win situation whereby for the film or program makers, the cost of production would be greatly reduced; whereas for companies, their products could be advertised in a more effective manner as they were indirectly promoted by famous actors in movies or programs [1]. In the world today, the popularity of product placements in motion pictures is now valued at $\$ 1.2$ billion annually and television revenues from product placements are now exceeding $\$ 1.8$ billion annually [1].

Consumer behavior has a history that is deeply intertwined with marketing history [2]. According to Jagdish and Sheth [2], both market and consumer behavior is strongly reliant on social as well as behavioral sciences. Both social sciences and behavioral sciences have overlapping fields which include anthropology, psychology, and sociology. Consumers in the 1940s made decisions based on rationality and calculations [9]. This means that they were very careful when purchasing a product or service because of they had lower purchasing power. There were a few behavioral hypotheses that were formed that postulated that consumers then were passive buyers because they were not given enough information of the products and services, therefore, they only bought according to their own knowledge about a certain good or service [9]. In the 1970s, consumers became problem solvers [9]. People started to search for more information [9] and began putting labels on products [9].

Throughout the 1940s to 1990s, all decision-making processes were made by the individual who then transitioned to a more collective one. As the years passed, the buying decision moved on to the younger generation. This is when the obsessive buying behavior occurred among college students, whereby they would overspend the credit cards given to them [10].

In Malaysia, a research was conducted to find out the severity of bankruptcy among Malaysians. The statistics by Malaysia Department of insolvency [11] show that 21\% who went bankrupt in the year 2012 were below 35 years old.

This indicates that consumer behavior has changed drastically from the 1940s (rational buyers) till now (overspent buyers). Consumers, especially younger ones, are buying products and/or services for self-esteem, fantasy, envy, remorse, and etc [11]. AKPK, The Credit Counselling and Debt Management Agency of Malaysia has reported that it is a trend today for young adults to overspend on "high-tech gadgets" and on activities that require a high cost. Youngsters are now spending more than they can afford, and ultimately, are unable to pay back their debts. In the case of obsessive buying behavior, a Chinese teen recently sold his kidney just to purchase an iPhone [12]. This shows how desperate consumers are these days to get what they want and not what they need even though they cannot afford the price. Therefore, the question that is raised now is: how great is the influence of product placement toward consumer behavior? Are there other factors that influence consumer behavior taken into account such as reference groups, online marketing sites, traditional advertising, and the trend of "keeping up with the Joneses"?

\section{PURPOSE OF STUDY}

This research is guided by the Theory of Reasoned Action, which suggests that people's behaviors are influenced by their intention. Attitude is then formed from that intention and he/she acts from that attitude which in turn forms their perception of life. People can predict behavior from an intention that is produced cognitively; these intentions then cause us to act out immediately as an automatic response. There are three factors that determine our intention: our attitude toward a specific behavior, our perception of social norms, and our distinguished behavioral control. In sum, the more positive we feel about an attitude and perception of social norms, the bigger the behavioral control, and the more the person will carry out the behavior based on his/her intention. In this study, the relationship between product placement will be tested based on personal factor (personal preferences) and subjective norms (social influence). This lays the groundwork for understanding the role of product placement towards influencing consumer behavior. A quantitative survey research using questionnaires will be conducted by developing closed-ended questions to determine the frequency and percentage of respondents' feedbacks. Sample size for this research is $\mathrm{N}=100$ which consists of teenagers ranging from age 18 to 25 . The respondents must have a tertiary education, and are located in the Klang Valley. This study may yield new insights into studying consumers' behavior and interests toward product placement which is regarded as part of an advertising initiative in the film and advertising industry.

\section{LITERATURE REVIEW}

A study was conducted to find out how attitudes are influenced by product placement types and the number of times they are repeated in a movie [13]. Basically, the aim of the researcher was to find out how consumers' attitudes are changed when they are exposed to brands that are repeated several times and when these exposures appear in a noticeable or a subtle way in the movie [13]. What motivated the researcher to conduct a study on this was due to the lack of research regarding this topic although product placement has become found increased use as a marketing tool [13]. The researcher's focus was on two different effects: repetition of product placements in a subtle way versus repetition of product placement in an obvious way [13]. Two different methods were used to test five different hypotheses. The first method was used to test the participants' foreknowledge of a 
few brands and their attitudes toward those brands; and to identify if repetitions of brands in obvious and subtle product placements create a positive or negative attitude toward the brand [13]. The results of this test showed that repetitions of brand in obvious product placements create a negative attitude toward the brand and vice versa. The second method was used to test the repeated product placements in a movie on viewers' attitude toward the show; their view on whether product placements are an intrusion while watching the movie; how obvious product placements affect their opinions on plot connection; and their perception toward reality of the movie after being exposed to obvious product placements [13]. Findings imply that repeated product placements that are obvious are most likely to create a negative attitude toward the show, perception of reality about the movie, and acts as an intrusion for consumers, as compared to subtle product placements. An exception is that repeated product placements have no effect on viewers' opinion on plot connection. Therefore, the researcher have drawn a conclusion that in order for product placements to be successful in movies, they must be less repetitive, less obvious so that they will not act as a distraction while consumers are watching a movie.

Research on consumer behavior and attitude after being exposed to product placement was conducted as well [14]. This research was done because university students were the samples for most past research [14]. In addition, limited research was done when analyzing the relationship between demography of consumers and the attitude [14]. In general, people have a positive attitude toward product placement with some exceptions of placement of illegal (drugs, beer, cigarettes) products. The researchers used an online survey to test the results of: the frequency of movie goers, feedback from peers regarding the movie, product placement existing attitudes, and product placement behaviors [14]. The results show that feedback from peers was the main contributing factor that determines consumer behavior and attitudes toward product placement [14]. The researchers gave several proposals for placement practitioners that it is most effective when a placement is done according to the genre of a film and the audience in general [14]. In addition, it gives the idea that more placements can be focused on positive audiences such as the African-American, females, and those under the low income category [14].

In the context of this study, product placement has indeed a direct influence on consumer behavior. There are a few factors that affect the attitude of viewers toward a particular brand in regards to product placement. Firstly, comparative appeal in movies; secondly, number of times brand appearing in the movie; thirdly, placement and audience characteristics on brand recall; fourthly, influence of actors in the movie; also, the obviousness of placement in movie; next, brands' target audience; besides that, the establishment of a brand; lastly, female characteristics and their influence on consumer behavior. The reason for its complexity is because there is no magic formula in changing consumers' brand attitude just in one or two movies. It goes beyond that because it affects the attitude, which then affects the buying intention, which influences the consumer's behavior. Therefore, advertisers must take note of these issues in order to place their brands more effectively to influence consumer behavior.

\section{METHODOLOGY}

The location of this study is the Klang valley which consists of Wilayah Persekutuan and Selangor. The population would be the young generation (18-25 years old) who are currently pursuing their tertiary education in the Klang Valley. A sample of 100 respondents was selected. The sample comprised of 100 university students. The gender of participants is not a controlled variable. The basic population was selected with the help of availability sampling. Questionnaires were distributed among students at universities around the Klang Valley.

To get the basic data for testing hypotheses, the method of survey questionnaire with the population have been used. The structured questionnaire comprised of closed-ended questions, which were used to get basic information of the sample as a method of data collection. The survey uses both descriptive and statistical methods to find the current situation regarding the use and impact of product placement toward consumer behavior.

\section{RESUlTS AND DisCUSSION}

The purpose of this study is to find out the influence of product placement toward consumer behavior. The data collected was based on the older Generation Y (18-25 years old) who are living in the Klang Valley. The research has investigated product placement from different aspects such as beliefs about product placement, attitude toward product placement, normative beliefs about product placement, subjective norms toward product placement, purchase intention and consumer behavior.

Altogether, six sections and five hypotheses were discussed and analyzed. As stated in Table I, all hypotheses were accepted positively.

TABLE I: THE OUTCOME OF HYPOTHESES TEST

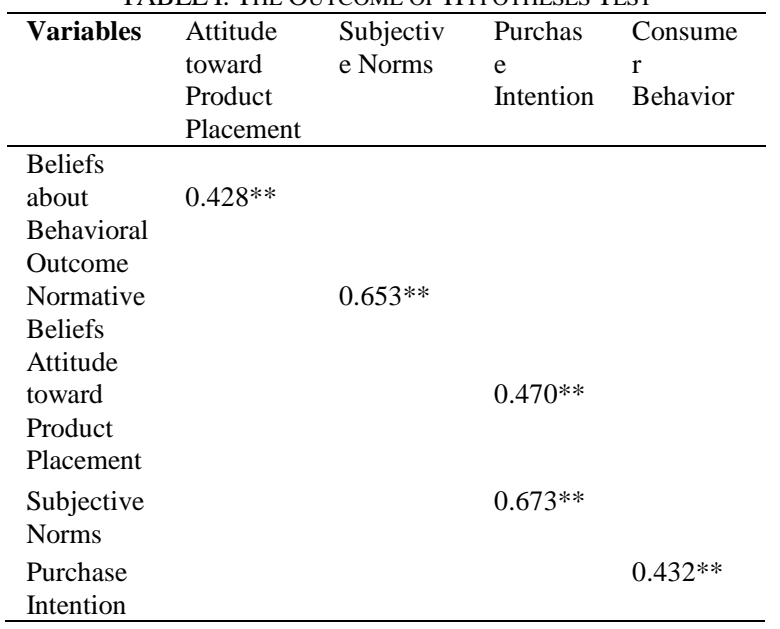

Nowadays, people are more exposed to movies and television shows compared to decades ago. As a result, the popularity of product placement as an advertising tool has increased due to the increase in media watching behavior. Based on this research, most young people believe that product placements must be placed subtly to avoid disturbing their watching experience. This was confirmed by similar previous study and found out that repeated placements in 
movies will act more as a disturbance rather than to garner a favorable view toward the product [15]. In addition, this research has shown that most respondents do not believe that product placements must be placed in an obvious way to make the movie/show more realistic.

In fact, product placements are already a disturbance based on the respondents' views. Therefore, in order to prevent placements from further damaging the brand, these products must be shown in more subtle ways in media so that it will create a positive attitude towards the brand [13].

However, there is an important point to take note about: people are more likely to accept placements when their favorite actor/actress mentions them verbally as in [15]. This promotes better audience recall of the brand as compared to placements that are not mentioned verbally. Hence, even though placements in general act as disturbances, they are more favorable when the audience's favorite actor/actress mentions them verbally.

Most of the respondents think that product placement is biased. This could indicate that certain brands are placed more frequently than other brands, or are placed in a more obvious way than other brands. A good example is the Apple brand and its placement in many movies recently [16]. Compared to other laptop brands such as Dell, HP, Toshiba, etc, Apple plays a prominent role in movies as compared to the rest and is a more preferred brand.

On the other hand, product placements seem to be very convincing according to the respondents in this research. Therefore, it is no surprise that the secret behind Apple's success is product placement [17]. Apple does not need to rely on any other advertising methods but on placing their products in movies and creating a buzz among media users via positive reviews [17]. This shows the ironic part of product placement whereby although people find that obvious placements are annoying, yet they are convinced by these placements.

As opposed to the two points mentioned, the respondents of this research do not think that product placements are pleasant, worthwhile, and valuable. This could be interrelated to their beliefs that product placements act more as a disturbance rather than something that is pleasant, worth watching, and valuable. The Theory of Reasoned Action also confirms that beliefs will have a direct impact on attitude [18]. Therefore, they do not appreciate much of the presence of placements unless they feature familiar and famous brands that might create a positive attitude instead of a negative one.

Most respondents in this research agree that family members and close friends would approve them to buy the placed product that they are interested in. This confirms the research that was conducted in Malaysia [19], whereby results show that family and groups do affect a person's values and beliefs. Malaysia is considered as a high context culture whereby the community is collective rather than individualistic. A high context culture person's identity originates from groups such as family and close friends, which is why approval from the family and close friends is an important aspect for the individual.

Most respondents agree that they will find out more information by trying the placed product that they are interested in. This includes free trials, samples, test drive, borrowing from friends, etc. In 2009, a research was done in America to find out their responses toward sampling. Eighty three percent of the population agrees that they like to be given free trials and can accept more openly samples that come with an advertising message [20]. Therefore, companies can use this method after placing their products in movies so that the audiences are able to try out their products.

Product placement works better in brand recall, brand recognition, and brand awareness as compared to purchase intention [15]. Placements in movies/TV show may be too short to trigger interest of the audience and the desire to purchase the product/service.

Lastly, consumer behavior is divided into four different sections: need recognition, information seeking, evaluation of alternatives, and purchase decision. Under the need recognition stage, most respondents in this research agree that product placements make them aware of new brands that they have never heard of. This could be an indication to advertisers that product placement can be another alternative in creating brand awareness, especially for new products and services. People might notice more about the brand when watching movies/TV shows as compared to the conventional advertising methods.

Under the information seeking stage, most respondents agree that they will search for more information about the placed product features they are interested in, such as size, color, quality, product attribute/features before making a purchase. People show their interest in a particular product or service when they start searching for information [21]. Therefore, it is very important for companies to state clearly their product features and ensure good reviews from people online so that those who are interested in the placed product can be further persuaded to purchase that particular product.

Under the evaluation of alternatives stage, most respondents in this research agree that they will compare alternatives based on functional features. This is related to the previous stage whereby respondents would search more information about the product functional features first when seeking for information.

Under the purchase decision stage, most respondents of this research would decide to purchase if the placed product is realistic and attractive. This may reflex that placements that are affordable, realistic, useful, and attractive are most effective when influencing consumer behavior.

Overall, this research proved that the Theory of Reasoned Action is a suitable model to test the influence of product placement toward consumer behavior. All hypotheses were accepted positively.

\section{CONCLUSION}

In summary, a millennial consumer's belief about product placement will affect his/her attitude toward product placement. A negative belief will produce a negative attitude. Lack of information and discussion about product placement causes him/her to rely on views from books/journals/news. There is also family element in this process because Malaysia belongs to a high context culture, and the identity of a person is based on his/her family background and views. This then 
affects the purchase intention, whereby he/she would prefer to try out the sample of the placed product than to make commitments to take up a loan to purchase the product. Finally, the consumer will make the purchase decision based on the functional features of the placed product that he/she is interested.

\section{REFERENCES}

[1] N. Jay, C. T. Salmon, and S. Chang, "The hidden history of product placement," Journal of Broadcasting and Electronic Media, vol. 50, no. 4, pp. 575-594, December 2006.

[2] F. Chan, "Product placement and its effectiveness: A systematic review and propositions for future research," The Marketing Review, vol. 12, no. 1, pp. 39-60, March 2012

[3] C. A. Russell and B. B. Stern, "Consumers, characters, and product: A balance model of sitcom product placement effects," Journal of Advertising, vol. 35, no. 1, pp. 7-21, Spring 2006.

[4] L. Tom. (24 January 2011). Thirsty, Simon? Or are you trying to sell us something? How product placement is about to transform British TV [Online].

Available: http://www.dailymail.co.uk/news/article-1349936/Simon-Cowells-A merican-Idol-Coca-Cola-product-placement-transform-UK-TV.html

[5] K. Leslie and S. Leon, Consumer Behavior, $10^{\text {th }}$ ed., New Jersey, US: Pearson Higher Ed, 2009, ch. 1, pp. 4-5.

[6] G. Belch and M. Belch, Advertising and Promotion: An Integrated Marketing, $9^{\text {th }}$ ed., New York, US: McGraw-Hill, 2012, ch. 4, pp. 110-115.

[7] A. Walton, "The evolution of product placement in film," The Elon Journal of Undergraduate Research in Communications, vol. 1, no. 1, pp. 70-85, Winter 2010.

[8] S. N. Jagdish.( July 1985). History of consumer behavior: A marketing perspective. Historical Perspective in Consumer Behaviour: Association for Consumer Research Singapore Conference. Singapore. pp. 5-7 [Online]. Available: http://www.acrwebsite.org/search/view-conference-proceedings.aspx? $\mathrm{Id}=12106$

[9] J. L. Zaichkowsky, "Consumer behavior: Yesterday, today, and tomorrow," Business Horizons, Elsevier, vol. 34, no. 34, pp. 51-58, Jun 1991.

[10] K. M. Palan, P. C. Morrow, A. Trapp, and V. Blackburn, "Compulsive buying behavior in college students: the mediating role of credit card misuse," The Journal of Marketing Theory and Practice, vol. 19, no. 1, pp. 81-96, Winter 2011.

[11] Malaysia Department of Insolvency. (February 17, 2013). Bankruptcy Statistic. [Online]. Available: http://www.insolvensi.gov.my/images/documents/Statistics/Bankrupc y/Statistik_Bankrap.pdf

[12] Reuters. (2012, April 6). Five charged after Chinese teen sells kidney to buy iPhone. Reuters. Retrieved from http://www.reuters.com/

[13] P. M. Homer, "Product placements: The impact of placement type and repetition on attitude," Journal of Advertising, vol. 38, no. 3, pp. 21-32, Fall 2009.

[14] F. Gregorio and Y. Sung, "Understanding attitudes toward and behaviors in response to product placement," Journal of Advertising, vol. 39, no. 1, pp. 83-96, Spring 2010.

[15] E. Bressoud, J.-M. Lehu, and C. A. Russell, "The product well placed: The relative impact of placement and audience characteristics on placement recall," Journal of Advertising Research, vol. 50, no. 4, pp. 374-385, January 2010
[16] S. Abe. (March 4, 2010). Why Apple Deserves an Oscar Too. [Online]. Available: http://www.theawl.com/2010/03/why-apple-deserves-an-oscar-too

[17] E. Jim. (August 5, 2012). Apple's biggest marketing secret was revealed in federal court. [Online]. Available: http://www.businessinsider.com/apples-biggest-marketing-secret-justgot-revealed-in-federal-court-2012-8

[18] K. Glanz, B. K. Rimer, and K. Viswanath, Health Behavior and Health Education: Theory, Research, and Practice $4^{\text {th }}$ ed., San Francisco, US: Jossey-Bass, 2008, ch. 4, pp. 67-92.

[19] A. Madahi and I. Sukati, "The effect of extemal factors on purchase intention amongst young generation in Malaysia," International Business Research, vol. 5, no. 8, pp. 153-160, August 2012.

[20] Promotional Products Association International. (PPAI). (December 8, 2010). The Effectiveness of Promotional Products as an Advertising Medium [Online]. Available: http://www.ppai.org/inside-ppai/research/documents/effectivemedium powertool.pdf

[21] A. Rohani and M. Nazari, "Impact of dynamic pricing strategies on consumer behavior," Journal of Management Research, vol. 4, no. 4, pp. 143-160, October 2012.

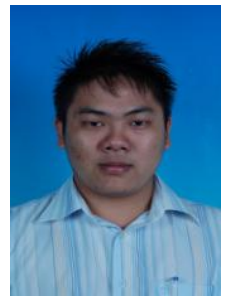

Liew Chee Kit was born near Kuala Lumpur, in Malaysia, on 13 August 1985. He gained a BSocSc (Hons) in Communication and Public Policy from The National University of Malaysia in 2008 and an $\mathrm{MSocSc}$ in Communication Management, also from The National University of Malaysia in 2011. He is currently pursuing a doctorate at The National University of Malaysia in communication.

$\mathrm{He}$ is currently a lecturer in the Department of Communication, at Infrastructure University Kuala Lumpur, in Kuala Lumpur, Malaysia. He is a keen lecturer in research methodology and political communication. He is familiar with both quantitative and qualitative research methodology. His research interest is in the rise and effects of new media on youth. His recent research topic includes the Usage of Mobilecasting and Leisure Activities of Malaysian Youth. He is a cheerful and energetic lecturer who motivates his students to think critically and evaluate facts in different dimensions.

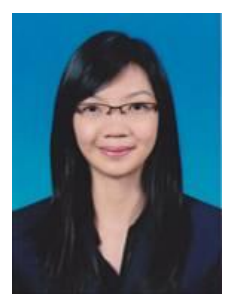

Elizabeth Lim Qui P'ng was born in Kuala Lumpur, in Malaysia, on April 20,1990. She gained a B.A, in marketing communication, from HELP University in 2012. She is currently a teacher at Sri Sempurna International School, in Kuala Lumpur, Malaysia.

She has a diverse experience in the marketing and teaching field. She was the Grand Prize winner of the Rev Up competition in 2011 whereby university students competed with each other in teams to organize the most ordinary yet extraordinary event. Her event was a success as she also worked with the Malaysia Association of the Blind (MAB). All profits earned from the event were donated to them and it was published in The Star Newspaper. In addition, she did her internship in one of Malaysia's most democratic workplace, SAYS.com and created the Padawan Internship Program for the company along with the other interns. She was also one of the two Malaysians who were selected to participate in the English Village program in Dankook University in 2011. This experience has given her the opportunity to teach English to Korean University Students. Besides, she taught Myanmar refugees for three months after graduation to attain exposure in the education field. Currently, she is a teacher in Sri Sempurna International School in Kuala Lumpur teaching Primary Year 4 students. 